\title{
A contribuição do estudo dos sons para a aprendizagem da língua
}

\section{Maria Helena Mira Mateus}

Faculdade de Letras de Lisboa (FLUL) e Instituto

de Linguística Teórica e Computacional (ILTEC)
Resumo: 0 estudo da fonética e da fonologia interessou desde muito cedo os linguistas, tanto nos seus aspectos gerais como na sua concretização numa língua particular. A partir do estruturalismo, a linguística moderna estendeu as suas análises por outros domínios como a morfologia e a sintaxe. Nas últimas décadas, 0 estudo dos sons conheceu um desenvolvimento específico com a atenção dada à prosódia na relação que possui com outros domínios da língua. Neste artigo procuro apontar os aspectos mais relevantes da fonética e da fonologia do português quer para a aprendizagem da ortografia, quer para a produção e compreensão da língua falada, quer para a utilização da prosódia apropriada às diversas circunstâncias do discurso oral.

Palavras-chave: Fonética; Fonologia; Prosódia
Résumé:L'étude de la phonétique et de la phonologie a intéressé les linguistes depuis toujours, soit au point de vue des aspects généraux, soit au point de vue de leur concrétisation dans les langues particulières. Après le structuralisme, la linguistique moderne s'est tournée vers d'autres domaines tels que la morphologie et la syntaxe. Pendant les dernières décades, l'étude des sons a connu un développement particulier en conséquence de l'attention accordée à la prosodie et à la relation qu'elle établi avec les autres domaines de la langue. Dans cet article je cherche à identifier les aspects les plus pertinents de la phonétique et de la phonologie du portugais par rapport à l'apprentissage de l'orthographe, à la production et la compréhension de la langue parlée ou à l'utilisation de la prosodie adaptée aux différentes circonstances du discours.

Mots-clé :Phonétique; Phonologie; Prosodie 



\section{Introdução}

Falar das unidades mínimas da língua nem sempre desperta o interesse (e muito menos a paixão) que sinto por estes estudos. Espero, no entanto, que o tema que aqui desenvolvo tenha pelo menos um pouco do encanto que tem para mim o estudo dos sons do português, sobretudo quando proponho aplicá-lo ao nível oral da língua. Assim, chamei a mim a agradável tarefa de tratar os sons da fala e dos sons da língua, ou seja, a fonética e a fonologia. Tentarei de seguida apresentar alguns argumentos em favor da contribuição destas áreas da linguística para a aprendizagem do português.

Começo por referir um aspecto da história da linguística que mostra como o estudo dos sons ocupou, de modo quase exclusivo, os primeiros trabalhos científicos neste domínio. É habitual considerar que foi na primeira década do século XIX que a linguística adquiriu estatuto de ciência desenvolvendo o que se pode considerar uma maravilhosa descoberta: a existência de parentesco entre o sânscrito e as línguas grega e latina, e a proposta de existência de uma origem comum para essas três línguas e para outras línguas europeias que passaram a ser designadas como indo-europeias. Esta descoberta desencadeou uma comparação sistemática entre várias línguas que poderiam provir de um mesmo tronco. Assim nasceu a linguística comparativa. A pouco e pouco, a análise comparada das línguas foi abrindo caminho para o estabelecimento da relação genealógica entre elas, criando a linguística histórica.

$\mathrm{E}$ o que se comparava entre as línguas? Estabeleciam-se comparações entre as vogais e consoantes existentes nos textos das línguas consideradas indoeuropeias e procurava-se propor um sistema fonético do indo-europeu. O Padre Nosso foi um dos principais textos que permitiu a comparação entre 55 variedades do indo-europeu como o Céltico, o Germânico, o Itálico, o Albanês, o Grego, o Báltico, o Eslávico, o Arménio, o Iraniano, o Indo-Ariano. As leis fonéticas eram 
consideradas responsáveis pela mudança das línguas (por exemplo, o $\langle$ p $>$ no início de palavra passou a $\langle\mathrm{f}\rangle$ como aconteceu com pater $>$ fater). $\mathrm{O}$ estabelecimento destas relações sistemáticas fez com que se passasse de uma comparação entre as línguas para a história das línguas.

Mas até aqui apenas se reconhece que estão em causa as letras, não os sons a que elas correspondiam, visto tratar-se, na sua quase totalidade, de línguas mortas, desaparecidas ou estudadas através da escrita. A par destes estudos criaram-se instrumentos para analisar foneticamente a articulação dos sons e alguns aspectos acústicos. Principalmente no Círculo Linguístico de Praga, com Trubetzkoi, Jakobson e outros linguistas que tinham profundo conhecimento de línguas eslavas e caucásicas, foram realizados, nas primeiras décadas do século $\mathrm{XX}$, estudos comparativos dos sistemas fonéticos de muitas línguas, distinguindo-se entre os elementos que constituiam o sistema, ou fonemas, e os sons que eram apenas variações fonéticas desses elementos: os fones ou variantes. No primeiro caso, o dos fonemas, trata-se de diferenças entre duas ou mais vogais ou consoantes que, ao alternarem, provocam uma alteração de significado, como sucede em português com /t/ de tom e /d/ de dom ou /a/ de bala e / $\varepsilon /$ de bela. No segundo caso, o dos fones, trata-se de uma variação fonética na realização de vogais ou consoantes que, ao alternarem numa palavra, não levam à alteração do seu significado, como sucede em português com a pronúncia de um /o/ em boi, quer seja só médio arredondado, [o], ou também palatalizado, [ö]. Esta diferença corresponde à dicotomia de Saussure entre língua e fala e criou a distinção entre fonologia e fonética. Em suma, a fonética descreve os aspectos articulatórios e as propriedades físicas de todos os sons que ocorrem na produção linguística e a fonologia estuda os sons que têm uma função na língua e que permitem aos falantes distinguir significados.

O interesse pelo estudo da língua falada levou mais tarde à descoberta da importância dos dialectos para 
o conhecimento da variação linguística. A dialectologia começou a desenvolver-se nos últimos anos do século XIX. Através dos estudos dialectais e das variações fonéticas, muito se pôde vir a saber sobre o contacto entre comunidades linguísticas, sendo possível esclarecer, em alguns casos, aspectos obscuros da respectiva história. Um exemplo do português é o conhecido /s/ beirão (o [s] ápico-alveolar que também se encontra no Brasil), herdeiro directo da consoante latina que tinha essa pronúncia, diferente do [s] dental, usado hoje em largas áreas do português europeu e brasileiro. Essa consoante dialectal, [s] ápico-alveolar, é, portanto, um vestígio da colonização latina e uma marca do carácter conservador das regiões em que se mantém.

Até este momento apontei apenas o interesse com que a linguística tem olhado para o estudo dos sons e a forma como a sua análise pode iluminar certos aspectos da história e do funcionamento interno das línguas. Chegou a ocasião de mostrar, de acordo com o título do artigo, em que medida o estudo desta área fundamental da língua pode contribuir para o ensino do português (o mesmo é dizer, de qualquer língua falada e ensinada).

\section{A aprendizagem da cidadania tolerante}

Antes de tudo convém chamar a atenção para o facto de que o estudo da fonética e da fonologia de uma língua é a descoberta do funcionamento da sua face exposta, daquele nível a que primeiro temos acesso quando ouvimos alguém falar. Muitas observações feitas por pessoas desconhecedoras da linguística incidem no domínio dos sons e constituem juízos de valor. Para a maioria dos falantes/ouvintes, as línguas, mesmo desconhecidas, são mais ou menos "agradáveis", algumas são mais "cantadas", outras mais "ásperas".

Por outro lado, também convém lembrar que, sempre que se trata de uma comparação entre dialectos, sociolectos (variações da língua ligadas a 
aspectos sociais) ou variedades nacionais de uma única língua (como as variedades europeia ou brasileira do português), os ouvintes diferenciam os falantes por possuírem este ou aquele "sotaque" e exercem muitas vezes julgamentos de valor: certas pronúncias são desprestigiadas, outras ridículas, há quem considere que aqui se fala "bem" ou "correctamente" e que ali a língua é "deformada" ou "incorrecta".

Nenhuma destas opiniões tem fundamento linguístico. Elas têm como origem o confronto com os sons a que os nossos ouvidos estão habituados ou baseiam-se em julgamentos de carácter social. Aliás, não há línguas melhores do que outras, ou mais aptas a transmitir certas noções ou conceitos. Já há muitos anos que pesquisas realizadas em sociolinguística mostraram que tanto as variedades dialectais quanto as variedades sociais ou nacionais possuem idênticas capacidades, em termos linguísticos, para expressar totalmente o que pretendem comunicar os falantes da respectiva variedade. A norma que se adopta em relação a uma determinada língua tem apenas, a seu favor, o prestígio social que lhe advém da utilização na escola, nos meios de comunicação social, no ensino como língua estrangeira. É deste ponto de vista que deve ser valorizada a sua aprendizagem, e não de outros pontos de vista exclusivamente linguísticos. Este é um trabalho de esclarecimento que compete ao professor educador.

Não podemos, por outro lado, esquecer que os falantes não manifestam apenas variações linguísticas dialectais ou sociais. Na escola portuguesa falam-se hoje cerca de 100 línguas diferentes; no Brasil muitos falantes têm línguas maternas autóctones ou provenientes de comunidades de imigração. É natural, portanto que, nestas circunstâncias, a pronúncia do português receba influência das línguas maternas dos respectivos falantes. Também nestes casos, evidentemente, a variação da língua não pode ser ridicularizada ou desprestigiada. Quando um aluno cabo-verdiano ou sueco não distingue 
fonologicamente entre $\mathrm{o} / \mathrm{r} /$ de para e $\mathrm{o} / \mathrm{R} /$ de parra, seria bom que o professor chamasse a atenção para a existência de diferentes sistemas fonológicos, e mostrasse que os alunos portugueses podem ter, igualmente, dificuldades em pronunciar alguns dos sons que funcionam em outras línguas, como por exemplo, o /ü/ palatalizado, do Francês ou o /r/ retroflexo do Inglês. Não nos competirá neste domínio passar a mensagem de uma cidadania tolerante?

\section{A Fonética e a Ortografia}

\subsection{Sistemas de escrita. Variação fonética e unificação ortográfica}

Vejamos agora a contribuição da fonética e da fonologia para a aprendizagem da ortografia, aspecto que adquiriu um valor social importante e por isso tem um lugar de relevo na aprendizagem de uma língua.

Como sabemos, nem todos os sistemas de escrita são alfabéticos - ou seja, nem todos se baseiam nos sons mínimos da fala utilizando, para os representar, símbolos que constituem o alfabeto, isto é, as letras. Além do alfabeto latino usado pelas línguas românicas ou germânicas, existem outros alfabetos como o cirílico, o grego, o árabe ou o hebraico e ainda outros, ideográficos ou logográficos de que é exemplo o chinês que tomam por base o morfema ou a palavra. Os sistemas alfabéticos são, contudo, mais económicos e maleáveis, já que o número de símbolos necessário para representar as palavras se torna muito mais reduzido do que nas escritas baseadas na palavra. Por esta razão os sistemas alfabéticos são actualmente utilizados por um grande número de línguas. No entanto, estes sistemas obrigam a um esforço de abstracção para distinguir os sons mínimos que constituem uma palavra e que são representados na escrita pelas letras, visto que esses sons ocorrem no contínuo sonoro da fala sem divisão entre eles. Na verdade, quem foi alfabetizado no início da escolaridade nunca tomou consciência dessa dificuldade quando aprendeu a escrever. 
${ }^{1}$ Este exemplo e a respectiva análise são da autoria de Luis Filipe Barbeiro. O alfabeto usado é o Alfabeto Fonético Internacional.

Além deste aspecto, a aprendizagem da escrita ainda inclui uma outra dificuldade que decorre do facto de cada palavra apresentar na fala uma variação de formas, ao passo que na escrita apenas pode ter uma forma gráfica, aquela que se ensina na escola e que é socialmente aceite: a sua ortografia.

O conceito de ortografia não é natural mas convencional, tendo dado lugar, desde há muito, a vivas discussões que põem em confronto perspectivas conservadoras e inovadoras. Pertence a estas últimas a chamada 'ortografia fonética' - uma ortografia que pretende aproximar-se tanto quanto possível da oralidade. Os defensores da ortografia fonética - que teve relevo, em Portugal, na segunda metade do século XIX - produziram textos com títulos como Escritura repentina. Nova tentativa de revolução orthographica (SOUSA, 1853); Escripta sem letras ou novo systema d'escripta syllabica (CALHEIROS, 1866) e advogavam a adopção de uma ortografia com base no sistema 'um som - uma grafia'. Porém, esta tentativa não vingou, e o conceito de ortografia manteve-se conservador e unificador em relação à variação fonética.

A forma ortográfica única representa as diversas pronúncias da palavra: dialectais, sociais ou de registo formal ou informal. Vejam-se as diferentes pronúncias da palavra escrever em português europeu ${ }^{1}$ :

\begin{tabular}{|c|c|c|}
\hline \multirow{7}{*}{$\begin{array}{l}\text { ortografia } \\
<\text { escrever }>\end{array}$} & \multicolumn{2}{|l|}{ fala } \\
\hline & a) & com a realização de todos os sons que também \\
\hline & [íf kriver] & se encontram representados na ortografia \\
\hline & b) & $\begin{array}{l}\text { com a não realização do som [i] inicial, } \\
\text { que }\end{array}$ \\
\hline & [Jkriver] & $\begin{array}{l}\text { corresponderia à letra }<\mathrm{e}>\text {, presente na } \\
\text { forma escrita }\end{array}$ \\
\hline & c) [ krver] & $\begin{array}{l}\text { com a não realização dos sons }[i] \text { inicial } \\
\text { e medial, que continuam presentes na } \\
\text { forma escrita }\end{array}$ \\
\hline & $\begin{array}{l}\text { d) } \\
{\left[\int \mathrm{kriveri}\right]}\end{array}$ & $\begin{array}{l}\text { com inserção do som }[\mathrm{i}] \text {, no final da } \\
\text { palavra após a } \\
\text { consoante }[\mathrm{r}]\end{array}$ \\
\hline
\end{tabular}


As formas a), b) e c) poderão ser ditas pela mesma pessoa, em situações diferentes: a forma a) em situações formais e as formas b) e c) em situações mais informais (...). A forma c) é provavelmente a mais frequente em Portugal; no entanto, não é essa a forma que se encontra consagrada na ortografia. A forma d) é característica de determinados registos sociais ou dialectais. Contudo, não tem uma representação ortográfica própria. $\mathrm{Na}$ verdade, apenas para indicar o modo de pronunciar de determinada região ou camada social, aceitamos que alguém escreva esta palavra acrescentando um <e $>$ ou um <i> no final para dar conta da inserção da vogal. Estas observações mostram que, para além de exigir o referido esforço de abstracção na identificação dos sons mínimos de uma palavra, a escrita também obriga a uma forma única perante a real variação fonética.

Voltando agora à relação entre a variação de pronúncia e a uniformização da grafia, repare-se nas especificidades que apresenta a ortografia de cada língua quanto à utilização correcta das letras. Essa utilização depende de muitos factores como a posição da letra na palavra (em Português actual, por exemplo, a letra <ç> nunca inicia uma palavra), as relações morfológicas entre palavras (a forma verbal traz, do verbo trazer, termina em $<\mathrm{z}>$, mas o advérbio trás, homónimo dessa forma verbal, termina em $\langle\mathrm{s}>$ ) ou aspectos lexicais ligados ao percurso histórico das palavras (passo com dois <ss $>$ e paço com $<$ ç têm a mesma forma fonética mas têm diferentes significados e escrevem-se de modo diverso conforme as formas latinas que estiveram na sua origem). Assim, um dos aspectos a ter em conta é o facto de a mesma letra poder representar sons diferentes e o mesmo som poder ser representado por letras diferentes. Esta possibilidade que nos é oferecida pela múltipla conjugação dos sons na formação de palavras é idêntica à que nos permite construir frases que nunca ouvimos, ou frases diferentes para exprimir a mesma ideia, usando o material que a língua põe à nossa disposição. Quando ensinamos uma 
${ }^{2}$ Ainda recorrendo a uma citação de Luís Barbeiro, apresento a escala de classificação para sistemas ortográficos de línguas europeias construída por Seymour (1997), sendo 1 mais transparente e 7 menos transparente: 1 - finlandês, italiano, espanhol; 2 - grego, alemão; 3 - português, holandês; 4 - islandês, norueguês; 5 - sueco; 6 - francês, dinamarquês; 7 - inglês, (cf. Vale, 1999, p. 24). língua, pode tornar-se mais evidente a grande riqueza que ela representa se pusermos em destaque a forma como os sons servem os nossos objectivos.

\subsection{Uma só letra representa sons diferentes.}

Por todas as razões indicadas, a aprendizagem da ortografia é complexa mas o seu grau de complexidade varia de língua para língua. Há línguas mais "transparentes", enquanto outras são consideradas mais "opacas", ou seja, apresentam uma maior dificuldade na determinação das relações entre os sons da palavra e a sua grafia ${ }^{2}$. Vejamos o que se passa com a língua portuguesa tendo em atenção alguns aspectos que são específicos do português europeu.

No que respeita às vogais: a mesma vogal pode representar diferentes sons.

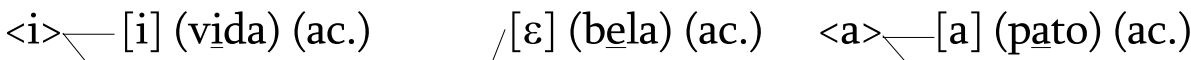

$$
\begin{aligned}
& \text { [j] (pai) } \quad[\mathrm{e}] \text { (medo) (ac.) } \quad \text { e }] \text { (calor) } \\
& <\mathrm{e} \times[\mathrm{r}] \text { (tenho) } \\
& \text { [i] (enorme) } \\
& \text { [i] (metia]) } \\
& \text { [j] (cear) }
\end{aligned}
$$

$$
\begin{aligned}
& \text { [o] (sol) (ac.) } \quad<\mathrm{u}>-[\mathrm{u}] \text { (muda) (ac.) } \\
& <\mathrm{o}>[\mathrm{o}] \text { (porto) (ac.) [w] (pauta) } \\
& \text { [u] (sapo) } \\
& \text { [w] (toalha) }
\end{aligned}
$$

As vogais indicadas como acentuadas (ac.) são tónicas. Pelo quadro se verifica que as letras $\langle\mathrm{e}\rangle \mathrm{e}\langle\mathrm{o}\rangle$ são as que cobrem maior número de realizações. No que respeita às vogais acentuadas, a distinção entre abertas e médias $([\varepsilon] /[\mathrm{e}] \mathrm{e}[\mathrm{o}] /$ [o]) não está representada por letras diferentes. A diferença de abertura entre estas vogais, que pode implicar uma diferença de significado (como bebo e bebe, ou rola, nome, e rola, v. rolar), é uma característica do sistema vocálico do português que o distingue de outras línguas como, por exemplo, o espanhol. 


\subsection{Vogais fonológicas}

Reparemos agora que há uma alteração constante entre a forma fonética (o som) que têm as vogais acentuadas e as não acentuadas (excepto [u] e [i] que se mantêm iguais). Esta alteração é sobretudo evidente no português europeu.
[a] e [e]; sapo/sapinho
$[\varepsilon]$, [e] e [1]; bebe, bebo/bebida
[o], [o] e [u]; come, como/comida

Esta regularidade mostra-nos que as acentuadas são fonológicas (porque a alternância entre elas sempre altera o significado) e as não acentuadas são a realização fonética dessas vogais quando átonas. Assim, temos em português, como vogais fonológicas, $/ \mathrm{o} / \mathrm{a} /, / \varepsilon /$, $/ \mathrm{e} /$; /Ј/, /o/, /i/, /u/. Estas sete vogais são representadas por cinco letras: $\langle\mathrm{a}\rangle,\langle\mathrm{e}\rangle,\langle\mathrm{o}\rangle,\langle\mathrm{i}\rangle,\langle\mathrm{u}\rangle$. A diferença entre o número de vogais fonológicas e o número de letras que as representam decorre da distinção fonológica que existe na língua portuguesa entre abertas e médias $(/ \varepsilon$, $\mathrm{e} /, \mathrm{o}, \mathrm{o} /)$.

\subsection{Algumas conclusões}

Vale a pena fazer agora o ponto da situação em relação ao que foi dito sobre o comportamento das vogais em português e a contribuição da fonética e da fonologia para o ensino da língua e, em especial, da ortografia.

(a) Em primeiro lugar, a distinção entre fonética e fonologia permite perceber o que são unidades fonológicas, os denominados fonemas. As unidades cuja substituição altera o significado da palavra são as unidades de que os falantes têm imagens mentais, e são as que os falantes reconhecem como sendo elementos do sistema fonológico da sua língua. Afinal, cada uma dessas vogais fonológicas é representada por uma só letra em português, 
quer a sua realização seja como tónica ou átona ou, mesmo, quando tem diferentes pronúncias dialectais. Estas e outras constatações permitem afirmar que a ortografia do português é basicamente fonológica.

Exercício: Se os alunos fizerem jogos de identificação de pares mínimos em que a substituição de um elemento por outro altera o significado da palavra é fácil reconhecer os fonemas da língua e relacioná-los com a sua grafia. Outros jogos de pronúncia distinguindo dialectos podem levar às mesmas constatações.

(b) Este reconhecimento das vogais fonológicas e da sua relação com as letras que as representam permite, ao mesmo tempo, dar algumas orientações sobre a sílaba em que incide o acento tónico. Pode também mostrar-se a necessidade de um acento gráfico quando pretendemos distinguir uma vogal aberta de uma média ainda que ambas sejam escritas com a mesma letra. (caso de muitas esdrúxulas como próximo, tétrico, péssimo, estômago, pêssego, etc.).

Exercício: Se no ensino da ortografia se usar como estratégia a realização de um léxico ortográfico (uma memorização da forma ortográfica das palavras), esse léxico pode servir para o conhecimento da utilização do acento gráfico e de outras grafias específicas como

(a) as letras que não representam nenhum som como o $<$ h $>$ em palavras como homem ou humano;

(b) os dígrafos que são conjuntos de duas letras com que se representa um único som (como $<\mathrm{lh}>$ que representa o som $[\lambda],<\mathrm{nh}>$ que representa $[\mathrm{n}]$ ou os dois $<$ rr $>$ ou dois $<$ ss $>$ que representam, respectivamente, $[R]$ e [s]); representação que só é exigida no interior da palavra e se não for precedida de $<\mathrm{l}>$ ou consoante nasal (palrar, honrado, sensação etc.).

Em todos estes casos o léxico ortográfico pode ser útil, pois a ortografia das palavras exige a sua memorização. 


\subsection{Um som pode ser representado por diferentes grafias}

O facto de a letra e o som não corresponderem exactamente permite que o mesmo som seja representado de diferentes maneiras. Um dos problemas que surge com frequência na aprendizagem da ortografia é o da representação das vogais nasais. Em português, a nasalidade das vogais representa-se com um til ou com uma consoante nasal a seguir à vogal. Veja-se o quadro abaixo:

[ĩ] <in, im $>$ (tinta, sim)

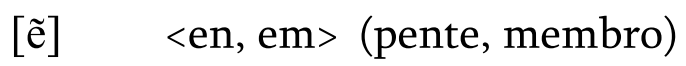

$[\tilde{\mathrm{e}}] \quad<\tilde{\mathrm{a}}>\quad$ (romã) $<$ an, am> (banco, ambos)

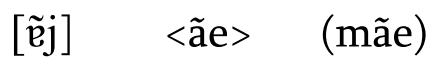
$<$ em, en> (tem, tens)

$[\tilde{\mathfrak{e}} \widetilde{\mathrm{w}}]<$ ão $>\quad$ (pão)

$<\mathrm{am}>\quad$ (formas verbais como amam, batam)

[ õ ] <on, om> (ponte, pombo)

[õ̃] <õe $>$ (corações)

[ũ] <un, um> (unto, atum)

Existem algumas regras ortográficas que permitem escolher entre as consoantes $<\mathrm{m}>$ e $<$ n $>$ para marcar a nasalidade: antes de $<\mathrm{p}>\mathrm{e}<\mathrm{b}>$ (consoantes labiais) usa-se $\mathrm{o}<\mathrm{m}>$ (consoante labial); antes das restantes consoantes usa-se $<$ n $>$. Por outro lado, em fim de palavra utiliza-se sempre $<\mathrm{m}>$.

Mas, pergunta-se: quando se representa a nasalidade com um til? Pode dizer-se que sempre que existe um ditongo se utiliza o til - excepto nas terminações de formas verbais da terceira pessoa do plural como falam ou batem ou têm. Fica por justificar a grafia de irmã, romã e outras palavras terminadas em <ã $>$ que podem fazer parte do léxico ortográfico ${ }^{3}$. 
Outro aspecto do problema relacionado com a ortografia é a troca sistemática de certas letras correspondentes a sons que se aproximam (por exemplo, a relação estreita entre duas consoantes líquidas $/ \mathrm{l} / \mathrm{e} / \mathrm{r} /$ ). Veja-se a representação do /r/ em alguns exemplos do português do Brasil:

"Vende-se-calvão e bujão" (Rio do Fogo, $\mathrm{RN})^{4}$

e o verso de cordel respectivo:

O autor desse caltaz

não era lá muito espelto

placa sempre se encomenda

para alguém que escreve celto

se pedirem minha ajuda

eu vou lá e até conselto (Rio do Fogo, RN)

${ }^{4}$ Estes exemplos são tirados de Camargo, 2007, pp. 44 e 45.
Mas há também grafias que obrigam à leitura em voz alta para compreensão do objectivo do escritor:

"orta d cove /aperte a campainha / sera atendida / 5 re de auface / 1 reau e cove" (Tabatinga, SP).

\subsection{Conclusões gerais}

Em conclusão do que até agora foi apresentado, a título exemplificativo, sobre a contribuição da fonética e da fonologia para a aprendizagem da ortografia, esta aprendizagem beneficia (a) da consciência do sistema fonológico da língua, (b) do conhecimento das relações entre vogais tónicas (ou acentuadas) e átonas, (c) da posição das letras na palavra, (d) da verificação da presença dos sons quando as palavras são pronunciadas com diferentes velocidades e (e) da constituição de um léxico ortográfico que permita memorizar a ortografia de palavras que são excepções a regras gerais. 


\section{Fonologia e Prosódia}

\subsection{0 que é a prosódia}

Que contribuição pode dar a prosódia - uma parte quase misteriosa do estudo dos sons - para o domínio do uso da oralidade em português?

David Crystal introduz a análise dos traços prosódicos com as seguintes palavras:

'Não é o que tu dizes mas a maneira como o dizes'. Este comentário familiar, imortalizado numa canção, indica de forma sintética tudo aquilo sobre que incide a análise prosódica. Os 'segmentos' da língua falada são vogais e consoantes que se combinam para produzir sílabas, palavras e frases (...). Mas ao mesmo tempo em que articulamos os segmentos, a nossa pronúncia varia noutros aspectos. Os elementos que provocam essa variação são os traços suprassegmentais ou prosódicos.

O conceito de prosódia esteve, até meados do século passado, ligado às características da poesia, ao ritmo do verso e ao tipo de rima (Versos decassílabos, rimas cruzadas). Hoje, porém, o estudo da prosódia tem um lugar fundamental no conhecimento de qualquer língua visto que a análise prosódica incide sobre aspectos do som que estabelecem relações entre si na cadeia sonora (por exemplo, o acento, que é um traço prosódico, relaciona sílabas acentuadas e não acentuadas como em fábrica e fabrica ou dúvida e duvida) ou entre essa cadeia sonora e outros domínios da língua (a entoação esclarece e completa muitas vezes o significado das frases (Vens jantar cá a casa? / Vens jantar cá a casa.).

Os traços prosódicos utilizam propriedades acústicas dos sons: a intensidade (ou força expiratória usada na fala), o tom (ou altura da voz, relacionada com a tensão ou a massa das cordas vocais) e a duração (ou 
tempo de articulação de um som, de uma sílaba ou de um enunciado). Estas propriedades são diferentes dos traços distintivos como a nasalidade ou a sonoridade, porque elas são inerentes a todos os sons, enquanto os traços distintivos podem estar, ou não estar, presentes num determinado som (por exemplo, o /e/ de vê é oral e o /ẽ/ de pente é nasal). Essas propriedades, que ocorrem simultaneamente com os traços distintivos, não alteram a qualidade fonética do som mas, ao estabelecerem entre si uma relação na sequência sonora, transmitem informação que também pertence ao significado da frase. Vejamos quais são os traços prosódicos e quais as suas funções.

\subsection{0 acento tónico}

No nível lexical, um aumento de intensidade e de duração cria o acento tónico, tornando uma das sílabas da palavra proeminente em relação às outras. Tradicionalmente, a localização do acento tónico em português leva à classificação das palavras em agudas (quando o acento incide na última sílaba), graves (quando incide na penúltima) e esdrúxulas (quando incide na antepenúltima).

Se o aluno for sensível à proeminência prosódica da sílaba acentuada poderá descobrir a diferença, na estrutura da palavra, entre o radical e os sufixos, e poderá ser orientado para criar palavras derivadas com sufixos, que mantêm, ou não mantêm, o lugar do acento. Derivados com sufixos -eiro(a), -oso(a), ou -zinho mostram uma deslocação do lugar do acento porque se formam novos radicais (veja-se por exemplo as palavras seguintes em que as sílabas acentuadas estão sublinhadas: sapato / sapateiro, óleo / oleoso, sorriso / sorrizinho). Outros sufixos não obrigam a alteração do lugar do acento como - vel, -ico (por exemplo, vencido / invencível, terror / terrífico). Estes exercícios são manipulações do léxico que, usadas de forma lúdica, 
podem despertar o interesse pela construção das palavras que os alunos, como falantes, utilizam.

A acentuação das formas verbais em português difere em muitos casos da das nominais. Na maioria das formas, o acento cai sobre a vogal temática (fala+va, part $i+$ sse etc.) mas existem outros casos de acentuação da vogal do radical (fal+o) ou da vogal do sufixo (bat+a+mos). Quem sabe, não são os próprios alunos a descobrir algum tipo de agrupamento das formas verbais no que respeita ao acento?

Além do acento principal, a palavra pode conter outros pontos de proeminência, os acentos secundários, que não atingem a intensidade do acento principal. Os acentos secundários (representados com uma aspa simples antes da sílaba, [']) reforçam o poder informativo do acento principal e organizam a cadeia fonética como um domínio rítmico. Em 'leitaría, em 'computadór, em 'poderóso ou 'papelaría existe um acento secundário na primeira sílaba e um principal na última do radical.

Os acentos principal e secundário têm uma grande importância na determinação do ritmo da fala quando se analisa a alternância de sílabas acentuadas e nãoacentuadas, e a consequente duração dos segmentos que constituem as sílabas. Essa alternância leva a atribuir às línguas dois tipos de ritmo: o ritmo acentual que decorre de uma tendência para as sílabas acentuadas ocorrerem em intervalos de tempo aproximadamente iguais, sendo variável o número de sílabas que existe entre duas tónicas, e o ritmo silábico que tem por base a unidade 'sílaba' que se repete com os mesmos intervalos de tempo. O português europeu e o português brasileiro têm sido diferenciados, por vezes, em função do tipo de ritmo que se considera caracterizar estas duas variedades: o europeu manifesta um ritmo acentual em consequência, sobretudo, da redução (ou supressão) das vogais átonas, e o brasileiro tem um ritmo silábico porque as vogais são todas audíveis e mantêm o número de sílabas da palavra. Levar os alunos a detectarem esta diferença de ritmo 
constitui um exercício de tomada de consciência de uma das mais evidentes razões para a estranheza que sentem os falantes das duas variedades do português.

\subsection{0 tom e a entoação}

A altura da voz, ou seja, o tom, depende da vibração das cordas vocais: quanto mais tensas estiverem ou quanto menor for a sua massa, mais alto pode ser um tom. Assim, as crianças falam com um tom mais elevado do que os adultos, as mulheres têm uma voz mais aguda do que os homens. $\mathrm{O}$ tom alto está muitas vezes associado a um aumento de intensidade como, por exemplo, quando chamamos alguém que está longe. Todos nós, de resto, podemos alterar o tom da nossa voz quanto tornamos as cordas vocais mais tensas. Este é um exercício que os alunos podem fazer e que lhes permite tomar consciência do que se passa no seu aparelho fonador quando fazem, por exemplo, "voz de falsete".

No que respeita à função do tom, lembre-se que existem línguas que se servem da diferença de tons com que é pronunciada uma vogal para opor diferenças de significado num mesmo contexto segmental. Em mandarim (chinês), por exemplo, existem quatro tons; alto, ascendente, descendente-ascendente e descendente. A palavra yi pode significar roupas, suspeitar, cadeira ou significado, conforme o tom que for aplicado sobre a vogal pela ordem acima indicada. Estas línguas chamamse línguas tonais.

Em português, porém, as diferenças de tom no mesmo contexto não distinguem significados. $\mathrm{O}$ que pode distinguir significados é a sequência de tons que abrange uma determinada frase. Esta sequência de tons cria a entoação de uma frase e por essa razão, línguas como o português são línguas entoacionais.

Na sequência sonora, existem pontos proeminentes que se manifestam por tons altos ou baixos, por vezes associados a uma maior intensidade. Aos limites direito 
e esquerdo da sequência associam-se os tons de fronteira. Muitas vezes, são esses tons de fronteira que permitem distinguir uma frase declarativa de uma interrogativa. Vejam-se as seguintes curvas simplificadas da frase "Amanhã vens jantar cá a casa" com diferentes entoações (representa-se o tom alto com $\mathrm{H}$ e o tom baixo com L; o tom de fronteira está representado por $\mathrm{H}$ ou $\mathrm{L}$ seguidos de i):

\begin{tabular}{|c|c|c|c|c|}
\hline [Amanhã & vens jantar & cá a & casa]I & (afirmação) \\
\hline $\mathrm{H}$ & & & $\mathrm{H}+\mathrm{L} \mathrm{Li}$ & \\
\hline [Amanhã & vens jantar & cá a & casa]I & (interrogação) \\
\hline $\mathrm{H}$ & & & $\mathrm{L}+\mathrm{H} \mathrm{F}$ & \\
\hline
\end{tabular}

Quando a interrogação é marcada lexical ou gramaticalmente (com quem, o que, o qual), a variação de altura faz-se em sentido descendente, próximo da afirmação. Veja-se o seguinte exemplo (frase "Quem comeu o bolo?"):

[Quem comeu o bolo]I

(interrogação)

$\mathrm{H} \quad \mathrm{H}+\mathrm{L} \mathrm{Li}$

Um exercício que permite dar consciência aos alunos da importância da entoação para diferenciar significados é o de construírem uma frase e pronunciála com entoações diferentes - declarativa, interrogativa, imperativa, persuasiva, sentimental - de forma a que seja possível determinar qual a informação que a entoação acrescenta ao significado lexical.

\subsection{0 acento enfático}

A proeminência de um elemento da frase pode simplesmente constituir um acento enfático para chamar 
5 Exemplos de Isabel Falé in Mateus, Falé e Freitas, 2005, cap. 3.4. a atenção do interlocutor. Os exemplos seguintes ${ }^{5}$ mostram as palavras que se pretende destacar escritas com maiúsculas:

. O GOLFINHO saltou por cima da rede.

. O golfinho SALTOU por cima da rede.

. O golfinho saltou POR CIMA da rede.

. O golfinho saltou por cima da REDE.

Vale a pena referir ainda a função das pausas na oralidade e a sua contribuição no desfazer de ambiguidades sintácticas, sobretudo na forma de agrupar os constituintes da frase. Exemplos largamente conhecidos são "O rapaz trouxe o livro da biblioteca" (trata-se de um livro que pertence à biblioteca ou de um livro que lá estava e o rapaz de lá o trouxe?) ou "Por favor, queria uma camisa para homem às riscas" ou, ainda, "O miúdo viu o irmão do professor que tem bigode" em que a colocação da pausa determina quem tem bigode: o professor (pausa a seguir a irmão) ou o irmão (pausa a seguir a professor). Podem imaginar-se inúmeros exemplos de organização da frase decorrente da localização de pausas e da sequência de tons.

A propósito de pausas, lembre-se que frequentemente se considera que os sinais de pontuação têm apenas como função representar aspectos prosódicos. Tomemos como exemplo a vírgula. Este sinal é muitas vezes entendido como a marca, na escrita, de uma pequena pausa que pode ocorrer na oralidade. Veja-se o seguinte exemplo em que dois sintagmas entoacionais (assim denominados por serem marcados pela entoação) são separados por uma pausa:

[O tapete encarnado do meu escritório] [precisa de ser aspirado com cuidado]

Trata-se, como se compreende, de uma oração constituída por um sujeito e um predicado. Como o sujeito 
é uma frase longa, ele pode ser seguido de uma pequena pausa que precede o predicado. Essa pausa é perceptível e leva, por vezes, à introdução na escrita de uma vírgula que assim fica colocada entre o sujeito e o predicado.

Ora sendo a vírgula um sinal de pontuação da escrita, a sua função não é a de marcar um aspecto prosódico, mas de organizar a frase mantendo juntos os seus constituintes - sujeito e predicado, predicado e objecto directo, etc. - e separando estes constituintes de outros que têm outro tipo de funções sintácticas. Veja-se o caso de uma oração relativa que, entre duas vírgulas, é uma explicativa ("A minha filha, que vive na Suécia, é casada" - significa que tenho apenas uma filha) ao passo que se não se encontrar entre vírgulas é uma oração restritiva (A minha filha que vive na Suécia é casada" - significa que tenho mais do que uma filha). A vírgula organiza a frase de um ponto de vista sintáctico e não prosódico.

Em suma, a entoação, quase sempre interrelacionada com os outros traços prosódicos, tem as seguintes funções na língua: emocional (para exprimir excitação, aborrecimento, surpresa), informacional (para indicar uma informação nova, por exemplo), textual (distinguindo a interrogação da afirmação ou da ordem), psicológica (organizando a língua em unidades que são mais facilmente percebidas e memorizadas) e identificadora (visto que pode ser uma marca de identidade que permite reconhecer a classe social a que pertence a pessoa ou, por vezes, a sua profissão) ${ }^{6}$.

Assim, a identificação de características rítmicas, entoacionais e acentuais do português pode ser utilizada para mostrar aos alunos que, ao servirem-se desses meios quando falam, podem tornar o seu discurso oral persuasivo, interrogativo, agressivo ou agradável conforme o desejarem, podem chamar a atenção para certos aspectos que consideram necessários e podem interessar e convencer os seus ouvintes. É inegável que o estudo da fala em que se considera a interligação de todos os factos prosódicos é um estudo aliciante e torna a
6 Veja-se David Crystal (1997), p. 173. 
aprendizagem da língua mais colorida, ao mesmo tempo que se apresenta como um domínio cheio de interrogações e de mistérios. 


\section{Referências}

BARBEIRO, Luís. Aprendizagem da ortografia: Princípios, dificuldades e problemas. Porto: Ed. Asa, 2006.

CAMARGO, José Eduardo e L. SOARES. O Brasil das Placas. Viagem por um país ao pé da letra. S. Paulo: Panda Books, 2007.

CRYSTAL David. The Cambridge Encyclopedia of Language. Cambridge University Press, 1997.

FROTA, Sónia e Marina VIGÁRIO. Constituintes prosódicos. In Mateus et al. (2003): Capítulo 26.3, 2003.

JAFFRE, Jean-Pierre. L'orthographe et la langue. Cahiers Pédagogiques. 440, Dossier: Orthographe, p. 11- 13, 2006.

MATEUS, Maria Helena Mira, Ana Maria BRITO, Inês DUARTE, Isabel FARIA, Sónia FROTA, Fátima OLIVEIRA, Gabriela MATOS, Marina VIGÁRIO e Alina VILLALVA. Gramática da Língua Portuguesa. 5a edição revista e aumentada. Lisboa: Editorial Caminho, 2003. (Capítulos 25 e 26).

MATEUS, Maria Helena Mira, Isabel FALÉ e Maria João FREITAS. Fonética e Fonologia do Português. Lisboa: Universidade Aberta, 2005.

RIO-TORTO, Graça Maria. Para uma pedagogia do erro. In Actas do V Congresso Internacional de Didáctica da Língua e da Literatura. Vol. I. Coimbra: Livraria Almedina, 2000, p. 595-618. 
